ORIGINAL RESEARCH ARTICLE

\title{
The Corporate Accelerator: A New Kind of Strategic Factor Market to Access Strategic Resources
}

\author{
Fernanda Arreola ${ }^{*}$, Véronique Favre-Bonte ${ }^{2}$ and Sébastien Tran ${ }^{3}$ \\ 'ISC Paris, Paris, France \\ IInstitut de Recherche en Gestion et en Economie (IREGE), IAE Savoie Mont Blanc, Université Savoie Mont Blanc, \\ Annecy, France \\ ${ }^{3}$ Léonard de Vinci Pôle Universitaire, De Vinci Research Center (DVRC), Paris, France and Université Paris Dauphine, \\ PSL Research University, France
}

\begin{abstract}
Corporate accelerators are often viewed as a way to capture innovation from startups. In this study, we present a fresh understanding of the specific role of corporate accelerators in accessing a number of strategic resources held by startups other than innovation. This research study explores the ways in which corporations use corporate accelerators to acquire resources held within the strategic factor markets in which startups compete. Using six in-depth case studies of corporate accelerators and 43 interviews with accelerators, corporations, and startups, we investigate the type of strategic resources that can be accessed by firms via corporate accelerators. We also explain the dynamics through which corporations gain access to some of these strategic resources.
\end{abstract}

Keywords: Corporate accelerator; Strategic factor market; Resource-based view; Startups; Innovation

Handling Editor:Thomas Roulet; Received: 22 July 20 | 9; Revised: XXXXXXXXXX; Accepted: I 8 November 2020; Published: I5 September 202 |

M ore and more corporations from diverse sectors have created corporate accelerators as startups support programs (Orange, Samsung, Intel, Airbus, etc.). Corporate accelerators can be defined as 'company-supported programs of limited duration that support cohorts of startups during the new venture process via mentoring, education, and company-specific resources' (Kohler, 2016, p. 348). The number of new accelerator programs has grown substantially since the launch of the popular acceleratorY Combinator in 2005.' The assumption is that this kind of new structure can support a part of the strategic goals, such as fostering innovation and diffusing entrepreneurial culture, by bringing the startup spirit into existing corporations (Gutmann, 2019). Consequently, corporate accelerators are becoming an integral part of the startup ecosystem (Kanbach \& Stubner, 2016; Moschner et al., 2019).

While, however, praising the advantages of corporate accelerators, little do we know about the way in which these

\footnotetext{
1. There are a few studies on the number of corporate accelerators in the world; however, the Global Accelerator Report identifies 579 accelerator programs worldwide supporting more than II,000 startups (Gust, 20 I6).
}

accelerators may capture valuable resources, other than innovation, and the dynamics that make these resources available to corporations. Moreover, a very few studies, to date, have examined the diversity of resources that can be accessed via corporate accelerators (Kohler, 2016; Mahmoud-Jouini et al., 2018; Weiblen \& Chesbrough, 2015). There is thus a clear gap, in both theory and practice, in our understanding of the mechanisms at work in corporate accelerators and how corporations can benefit from them.

The previous research studies have viewed the role of corporate accelerators mainly as sources of innovation (Kohler, 201 6; Richter et al., 201 8; Shankar \& Shepherd, 2019). However, startups may hold other valuable resources (breakthrough technology, innovative solutions, etc.) that can be a potential source of competitive advantage through early recognition of the threats and competition (Richter et al., 2018; Shankar \& Shepherd, 2019).

In parallel, the research study on strategic resources has relatively paid close attention to the way in which corporations gain access to valuable resources. According to the resourcebased view (RBV), a strategic resource meets certain criteria: it

*Corresponding author: Fernanda Arreola, Email: farreola@iscparis.com 
is valuable in that it reduces costs or increases the value for customers, rare enough that competitors cannot use the same resource to successfully compete with the value, difficult to imitate and non-substitutable (in other words, 'there cannot be strategically equivalent substitutes for this resource that are valuable but neither rare or imperfectly imitable' (Barney, 1991, p. 106). The RBV postulates that such resources are acquired in strategic factor markets (SFMs) (Barney, 1986); however, less is known about how firms compete for these resources in external competitive markets. Scholars have specifically called for more research to clarify how firms can reduce the uncertainty of resource acquisition through a better evaluation or appraisal of their value (Foss, 20l I).

This study examines the specific role of the corporate accelerator as a new way for corporations to absorb, acquire, and even test the value of new resources. Indeed, there has been very little research on what corporations themselves seek from hosting such startups (Hausberg \& Korreck, 2020; Kupp et al., 2017). Thus, the theoretical and practical interest of this study is to better understand what kind of resources held by startups are available to corporations and the dynamics at play. This study is, therefore, based on the following research question: what are the specific aspects of corporate accelerators and the mechanisms through which corporations can capture strategic resources from startups?

We offer a fresh perspective by exploring a wider set of resources that corporations may acquire through corporate accelerators within the framework of the RBV. By an analysis of six in-depth case studies of corporate accelerators in France, we explore the motives that lead corporations to create accelerators and consequently can obtain the diversity of resources. Adopting the lens of SFM, our first contribution is to show the value of the corporate accelerator as a means for using, integrating, evaluating, or acquiring competitive resources that come from the SFM where startups compete (Barney, 1986). Afterwards, we outline the diversity of resources held by startups (other than innovation) and highlight the need for further insights into the dynamics of how these assets produce value for corporations (Leiblein et al., 2017; Serrano \& Ziedonis, 2019). We conclude by suggesting a new research avenue to further explore the concept that startups interact in a specific SFM in which corporate accelerators play a unique role.

This research article is structured as follows: first, we analyze the existing literature on corporate accelerators and the startup-held resources that corporations can access in a bid to highlight the gaps in the literature and with a framework anchored in the RBV and SFM literature. Second, we explain the methodology used in this study. We then present the research findings, before discussing the specific role of corporate accelerators in the acquisition of strategic resources from startups as a source of strategic competitive advantage for corporations.

\section{Theoretical background}

The first subsection provides an overview of how the literature has explored corporate accelerators, and then the second subsection explores the underlying concepts of how corporations acquire the resources needed to create or strengthen their competitive advantage.

\section{A brief review of the role of corporate accelerators}

The increasing need for more agile innovation and R\&D processes has led firms to seek innovative ways of ensuring access to new technologies and ideas. A relatively recent model for sourcing such innovations is the corporate accelerator. Accelerators offer 'fixed-term, cohort-based programs, including mentorship and educational components that culminate in a public pitch event or demo day' (Cohen \& Hochberg, 20 I4, p. 4). As opposed to incubators, accelerators 'are not primarily designed to provide physical resources or office support services over a long period of time (and) their focus is on early-stage tech start-ups for which the costs of experimentation have dropped significantly in the last decade' (Pauwels et al., 2016 , p. 14). More specifically, corporate accelerators are outside-in open innovation initiatives that seek to provide the sponsoring firms with access to startups' innovative ideas and mindsets (Richter et al., 20 I 8; Weiblen \& Chesbrough, 20I5).

In terms of their utility to the parent corporation, corporate accelerators are designed to be intermediates that bridge the gap between startups and corporations (Kohler, 2016). Corporations leverage liability of size, newness, and lack of access to strategic resources (Kohler, 2016), while protecting startups from corporate inertia, giving them a sufficient space and flexibility to adapt their offer without falling into the traps inherent in the nature and constraints of more stable business models (Weiblen \& Chesbrough, 2015). Until recently, the literature on accelerators only provided a limited understanding of how this innovation was sought and pursued (Kanbach \& Stubner, 2016; Shankar \& Shepherd, 2019).

Most of the literature exploring the dynamics of corporate accelerators has, therefore, been built on the premise that these entities are created with the main purpose of boosting innovation for corporations (Becker \& Gassmann, 2006; Kohler, 2016). Such innovation has been studied from several perspectives. The first relates to the form of knowledge produced. Becker and Gassmann (2006) defined four such types of knowledge, which includes entrepreneurial, organizational, technological, and market-oriented knowledge. A second stream of literature focuses more on technological innovation, claiming that startups can be a source of incremental and disruptive innovation (Kanbach \& Stubner, 2016). Other than these 'bringing outside-in innovation' typologies, there is little 
information as to why corporate accelerators are set up (Hausberg \& Korreck, 2020; Mahmoud-Jouini et al., 2018). A few studies have argued that there are additional positive effects for firms in being so close to startups, including an impact on the corporate culture (Kohler, 2016) and the potential to enhance their reputation in a way that can help attract talent (Richter et al., 20।8). The existing research study leaves an opportunity to further evaluate the reason why accelerators are set up (Hausberg \& Korreck, 2020; Mahmoud-Jouini et al., 20।8). Furthermore, there is a need to better understand the evolution of corporate accelerators, as well as the mechanisms and dynamics that play a role in the outcomes and resources that can be found thanks to them (Shankar \& Shepherd, 2019).

\section{A review of strategic factor markets}

From the resource-based view, which has been increasingly adopted as the literature of reference for exploring the value of resources within a firm (Barney, 2001; Wernerfelt, 1984), in order to develop a sustainable competitive advantage, corporations need to find resources that are rare, valuable, difficult to imitate, and substitute (Barney, 1991). These include strategically relevant resources that 'enable a firm to efficiently and effectively develop and implement a strategy that, in turn, generates superior performance' (Barney \& Arikan, 200I, p. 143). Such resources can be either created by the firm or acquired (Barney, 200 I). One of the key characteristics of these resources is that their supply is inelastic, making them a source of competitive advantage (Peteraf, 1993). Another key characteristic is their causal ambiguity, which means that the value of the resources is uncertain, and the firm is unable to anticipate their future value to the organization (Lippman \& Rumelt, 1982).

Strategic resources imply a supply inelasticity explained by their rareness. Such resources take a long time to produce, are difficult to sell or acquire, and are intrinsically associated with the complex operations of each firm, making them extremely heterogeneous in nature (Barney, 1991). Their capabilities are embedded within a business's operations and are reliant on organizational routines (Barney, 200I). Notwithstanding, both strategic resources and capabilities respond to the principle of causal ambiguity, which means that as their nature is difficult to explain, they are hard for competitors to copy or appropriate (Lippman \& Rumelt, 1982).

The RBV and its extensions suggest that all of the differentiated resources determine the positioning of a firm against its competitors (Barney, 1991; Grant, 1991; Peteraf, 1993; Wernerfelt, 1984). Furthermore, these firms can obtain a sustainable competitive advantage depending on the extent to which they can exploit and protect the resources (Grant, 1991). When a firm lacks these competitive resources, it must seek them externally or find ways to develop them internally in what is known as a strategic factor market (Makadok \& Barney, 200I).

SFMs are defined as 'market(s) where the resources necessary to implement a strategy are acquired' (Barney, 1986, p. I,2।3). The concept of SFM borrows from the same inherent logic as the thinking of economist David Ricardo (Grant, I 991). The efficiency of these factor markets is determined by the lack of 'arbitrage' opportunities between their members. In other words, as no one has precise information about the value and incidence of each resource available on these markets on a firm's strategy, no one can claim to create an advantage by the simple fact of acquiring them (Barney, 1986). A fundamental characteristic of SFM is that firms will have a difficult time to establish the real value of the resources they acquire as they are unable to anticipate the value of bringing them into the organization. In addition, they are unable to determine beforehand whether such resources can be properly integrated into the firm's culture and dynamic.

This concept of SFM by shedding light on how the company seeks the resources it needs (internally or externally) can help us to understand the mechanisms at work and how the corporate accelerator can bring valuable resources to the corporation. Departing from the preceding literature review, this study addresses a gap in the literature that helps answer the following research question: what are the specific aspects of corporate accelerators and the mechanisms through which corporations can capture strategic resources from startups?

\section{Methodology}

We followed an inductive research approach based on multiple case studies to make generalizable findings (Eisenhardt, 1989). First, we analyzed each case to establish an understanding of the individual corporate accelerator. We then compared the cases to identify the similarities and differences between them for further development of theoretical framework (Glaser \& Strauss, 1967). Building on this approach, we analyzed the extant outcomes in the field of corporate entrepreneurship research (Weiblen \& Chesbrough, 2015).

\section{Data collection}

Our sample consists of six corporate accelerator case studies, which are selected according to a structured approach. ${ }^{2}$ We focused on corporate accelerator programs that met the following criteria: (1) accelerators that have existed for over a year, (2) ongoing activity with at least one employee working

\footnotetext{
2. This is an opportunistic or emergent sampling. Indeed, as this research study is exploratory and little is known about the issue, this method is considered to be suitable (Cohen \& Crabtree, 2006).
} 
Table I. Presentation of the six corporate accelerators

\begin{tabular}{|c|c|c|c|c|c|c|c|}
\hline $\begin{array}{l}\text { Name of the } \\
\text { entity }\end{array}$ & Interviewee & $\begin{array}{l}\text { Date of } \\
\text { creation }\end{array}$ & Business sector & $\begin{array}{l}\text { Length of stay } \\
\text { for hosted } \\
\text { startups }\end{array}$ & Team in the entity & $\begin{array}{l}\text { Number of } \\
\text { startups hosted }\end{array}$ & $\begin{array}{l}\text { Similar entities } \\
\text { worldwide }\end{array}$ \\
\hline Orange Fab & $\begin{array}{l}\text { Head of } \\
\text { accelerator }\end{array}$ & 2013 & $\begin{array}{l}\text { Telecom } \\
\text { New technologies }\end{array}$ & 3-6 months & $\begin{array}{l}5 \text { people and a network of } \\
\text { coaches and mentors }\end{array}$ & $\begin{array}{l}\text { Between } 30 \text { and } \\
35 \text { startups a year }\end{array}$ & Yes (14 in 2018) \\
\hline Capgemini & $\begin{array}{l}\text { Head of } \\
\text { accelerator }\end{array}$ & 2011 & Consulting IT & $\begin{array}{l}\text { From I day } \\
\text { to } 6 \text { months }\end{array}$ & $\begin{array}{l}\text { One person and a network of } \\
\text { experts from CG business units } \\
\text { or external experts }\end{array}$ & $\begin{array}{l}\text { More than } 200 \\
\text { startups since its } \\
\text { creation }\end{array}$ & $\begin{array}{l}\text { Yes }(30 \text { at } \\
\text { the end of } \\
2018)\end{array}$ \\
\hline $\begin{array}{l}\text { WAI (BNP } \\
\text { Paribas) }\end{array}$ & $\begin{array}{l}\text { Head of } \\
\text { accelerator }\end{array}$ & 2015 & Banking sector & 6 months & $\begin{array}{l}\text { Two people and a network of } \\
\text { experts in the banking sector, } \\
\text { and a coach and a sales expert }\end{array}$ & $\begin{array}{l}30 \text { startups a } \\
\text { year }\end{array}$ & No \\
\hline BetaGouv & $\begin{array}{l}\text { Head of } \\
\text { accelerator }\end{array}$ & 2013 & Public administration & $\begin{array}{l}\text { Maximum } \\
6 \text { months }\end{array}$ & $\begin{array}{l}\text { Eight people and a network of } \\
\text { experts from public administration } \\
\text { or external consultants }\end{array}$ & $\begin{array}{l}55 \text { startups a } \\
\text { year }\end{array}$ & No \\
\hline $\begin{array}{l}\text { Le Village by } \\
\text { CA (Crédit } \\
\text { Agricole) }\end{array}$ & $\begin{array}{l}\text { Head of } \\
\text { accelerator }\end{array}$ & 2014 & Banking sector & 2 years & $\begin{array}{l}\text { Eight people and a network of } \\
\text { experts from corporate partners } \\
\text { or external experts }\end{array}$ & $\begin{array}{l}190 \text { startups } \\
\text { since its creation }\end{array}$ & $\begin{array}{l}\text { Yes (one in } \\
\text { Italy) }\end{array}$ \\
\hline $\begin{array}{l}\text { Start'inPost } \\
\text { (La Poste) }\end{array}$ & $\begin{array}{l}\text { Head of } \\
\text { accelerator }\end{array}$ & 2014 & Mail delivery service & 3-4 months & $\begin{array}{l}\text { One person and a network of } \\
\text { experts from La Poste business units }\end{array}$ & $\begin{array}{l}60 \text { startups } \\
\text { since its creation }\end{array}$ & No \\
\hline
\end{tabular}

for the program full-time, (3) location of the accelerator in Paris (France), and (4) finally, a strong link between the accelerator and the corporation. We selected corporate accelerator programs in Paris due to their strong presence in this city and our potentially easier access to their program managers.

Data collection spanned 12 months (between May 2018 and March 2020) ${ }^{3}$ and included the data collection preparation, field interviews, direct observations, secondary data collection, and transcription activities. We used multiple sources of data to facilitate triangulation (Denzin \& Lincoln, 20I I), including publicly available materials, such as news articles, press releases, corporate websites, and corporate accelerator websites. However, the amount of material produced internally by corporate accelerators is limited because there are young, small, and agile entities working within the corporation. We also had access to promotional brochures and manuals, which helped us to understand the organizational context and strategy. Consistent with most qualitative, inductive research (Eisenhardt, 1989), this study relied on semi-structured interviews as its primary data source. The interviewees included corporate accelerator executives from each of the six corporate accelerators, with two to three startup founders hosted by each of the six corporate accelerators and

\footnotetext{
3. We visited the accelerator in the period of May-October 2018 (in this phase, we were in semi-ignorance of both the literature on corporate accelerators and precise knowledge on the strategic orientations of such accelerators). We then worked on the data analysis before moving on to the literature (to see whether our study findings were new or had already been documented), and we briefly went back to the accelerators in Spring 2019 (for 4 months) and to corporations in Spring 2020 (for 2 months) just to gather some missing information via follow-up conversations with the interviewees, which helped us to clarify and/or validate the results of this study.
}

executives attached to the corporate accelerator in each of the six corporations (two to five executives from each corporation). The interviewees were selected for their ability to give us complementary views of the three different types of actors that interact with the accelerator (corporation representatives, heads of accelerators and startups; see Table I).

In total, the study sample consisted of 43 semi-structured interviews ( 6 heads of corporate accelerators, 24 executives from 6 corporations and 13 startup founders). Each interview lasted between 60 and 90 minutes, and all were recorded. We used three interview guides (one for each entity). The corporate accelerator interviews were loosely structured around three areas: the characteristics of corporate accelerators, motives (why the corporations run these programs), and evolution of the corporate accelerators. The corporation interviews were also organized around three areas: why the corporation decided to launch a corporate accelerator, the links between the corporate accelerator and the corporation (and the type of resources held by the corporate accelerator), and the way the corporation captures these resources.

The interviews with the startups covered three areas of questioning (in addition to learning about their entrepreneurial activity), which helped us to triangulate the data. These are related to their motives for joining a corporate accelerator, the way they collaborate with the corporate business units, and the resources and skills they benefit from (see Table 2).

\section{Data analysis}

The data collected through interviews, documents and direct observations were analyzed using a qualitative inductive 
Table 2. Startups hosted in the corporate accelerators

\begin{tabular}{|c|c|c|c|c|}
\hline Startups & Interviewee & Entrepreneurial activity & $\begin{array}{l}\text { Corporate } \\
\text { accelerator }\end{array}$ & Main reasons for being hosted by the corporate accelerator \\
\hline PhD Talent & $\mathrm{CEO}$ & $\begin{array}{l}\text { Consulting and annual job } \\
\text { fair for researchers }\end{array}$ & $\begin{array}{l}\text { WAI BNP } \\
\text { Paribas }\end{array}$ & $\begin{array}{l}\text { To be in an innovation ecosystem } \\
\text { Mentoring by experts from the accelerator } \\
\text { Business development with the bank's (BNP) business customers }\end{array}$ \\
\hline Energic & Co-founder & $\begin{array}{l}\text { Innovative energy solutions } \\
\text { for companies }\end{array}$ & $\begin{array}{l}\text { WAI BNP } \\
\text { Paribas }\end{array}$ & $\begin{array}{l}\text { To develop commercial partnerships with the bank's business } \\
\text { customers. } \\
\text { Mentoring by experts from the accelerator. } \\
\text { The accelerator is a 'guarantor' for the startup. }\end{array}$ \\
\hline Entr'Up & CEO & $\begin{array}{l}\text { Intelligent platform to organize } \\
\text { and manage meetings }\end{array}$ & Orange Fab & $\begin{array}{l}\text { To sell the platform to Orange and create } 3 \text { Proof Of Concepts } \\
\text { (POC) with business units. The accelerator helped to sign contracts } \\
\text { with internal business units and provided experts to mentor the } \\
\text { startup. }\end{array}$ \\
\hline Global Exam & $\mathrm{CEO}$ & $\begin{array}{l}\text { e-Learning platform for } \\
\text { language training }\end{array}$ & Orange Fab & $\begin{array}{l}\text { To develop commercial partnerships with Orange business units } \\
\text { (access to their platform via the Internet Box) in France and with } \\
\text { some business customers abroad. }\end{array}$ \\
\hline Neuro-profiler & $\mathrm{CEO}$ & $\begin{array}{l}\text { Finance profiling tool for banks } \\
\text { based on behavioral finance }\end{array}$ & Orange Fab & $\begin{array}{l}\text { The main goal was to create a business partnership with Orange } \\
\text { bank and to promote the solutions. }\end{array}$ \\
\hline Copsonic & $\mathrm{CEO}$ & $\begin{array}{l}\text { Wireless and audio solutions } \\
\text { for loT, smart detection, digital } \\
\text { security }\end{array}$ & $\begin{array}{l}\text { Capgemini } \\
(\mathrm{CG})\end{array}$ & $\begin{array}{l}\text { To develop commercial partnerships with large companies that are } \\
\text { CG customers. Copsonic sells licenses based on its innovation, and } \\
\text { CG offers consulting services to incorporate them. The corporate } \\
\text { accelerator is 'a well-known brand' for Copsonic. }\end{array}$ \\
\hline$X X \|$ & $\begin{array}{l}\text { Head of } \\
\text { communi- } \\
\text { cation }\end{array}$ & $\begin{array}{l}\text { Software provider with new } \\
\text { technologies based on virtual } \\
\text { reality and augmented reality } \\
\text { for firms }\end{array}$ & $\begin{array}{l}\text { Capgemini } \\
(\mathrm{CG})\end{array}$ & $\begin{array}{l}\text { The start-up was looking for an integrator for its innovative solution } \\
\text { (co-design of } 3 \text { Minimum Viable Products with CG). Ability to 'scale } \\
\text { up' development with CG, and meet new prospects and the relevant } \\
\text { people to sign sales contracts. }\end{array}$ \\
\hline Peek-sprint & CEO & $\begin{array}{l}\text { Postcard printing with a } \\
\text { terminal from a smartphone }\end{array}$ & Start'inPost & $\begin{array}{l}\text { To develop commercial partnerships with business units of La Poste } \\
\text { (creation of two POCs with financial help from the accelerator). The } \\
\text { idea is to raise its profile and be more legitimate in the eyes of other } \\
\text { companies. }\end{array}$ \\
\hline Visiperf & $\mathrm{CEO}$ & $\begin{array}{l}\text { Marketing campaigns, SEO, } \\
\text { search engine indexation }\end{array}$ & Start'inPost & $\begin{array}{l}\text { To develop commercial partnerships with business units from La } \\
\text { Poste (POC with a La Poste subsidiary that sells services for SMEs } \\
\text { but with no contract). One of the goals was to raise funds from La } \\
\text { Poste in a context of strategic change for Visiperf. }\end{array}$ \\
\hline $\begin{array}{l}\text { France- } \\
\text { Connect }\end{array}$ & $\begin{array}{l}\text { Product } \\
\text { Director }\end{array}$ & $\begin{array}{l}\text { FranceConnect is a service } \\
\text { that allows users to identify } \\
\text { existing certified accounts for } \\
\text { government services }\end{array}$ & BetaGouv & $\begin{array}{l}\text { To accelerate the platform's creation and include services that are } \\
\text { widely sought by citizens but are difficult to find (scams, poor } \\
\text { referencing, etc.) }\end{array}$ \\
\hline API & $\begin{array}{l}\text { Web } \\
\text { Developer }\end{array}$ & $\begin{array}{l}\text { Government IT, API provision } \\
\text { to make access to public data } \\
\text { easier }\end{array}$ & BetaGouv & $\begin{array}{l}\text { To facilitate development of a 'commercial' tool outside traditional } \\
\text { government entities. }\end{array}$ \\
\hline Fan Voice & CEO & $\begin{array}{l}\text { Digital marketing, consumer- } \\
\text { packaged goods, data mining } \\
\text { and customer reach }\end{array}$ & $\begin{array}{l}\text { Le Village by } \\
\text { CA }\end{array}$ & $\begin{array}{l}\text { To benefit from commercial development opportunities, the } \\
\text { legitimacy of being part of a larger group and the facilities (meeting } \\
\text { rooms, etc.). }\end{array}$ \\
\hline $\begin{array}{l}\text { Baguette } \\
\text { Academy }\end{array}$ & $\begin{array}{l}\text { Business } \\
\text { Developer }\end{array}$ & E-learning & $\begin{array}{l}\text { Le Village by } \\
\text { CA }\end{array}$ & $\begin{array}{l}\text { Commercial relationship opportunities provided by the accelerator } \\
\text { and legitimacy. Opportunity to leverage from CA employees' } \\
\text { contacts within agricultural/ or food industries }\end{array}$ \\
\hline
\end{tabular}

approach (Gioia et al., 20।3) and a manual coding process. An independent researcher who did not take part in any of the interviews provided us feedback and asked us questions on the data gathered in the later part of the analysis for greater validity of the interpretations. Moving from the data to the relevant literature, we developed a clearer understanding of the type of resources held by startups and sought by corporations. This information was further analyzed using the transcript coding process and interpretation of its fit with the emerging themes (cf. Figure I). We began our analysis by identifying the activities and operations of startups to understand their key characteristics in terms of resources. We also observed how 
they interacted with the corporate accelerator. We undertook a first-order analysis of these activities, which involved full coding of the interviews, company documentation and informal discussions. Once we had gathered all of the data, we attempted to identify words and phrases that represent similar groups of text. For example, these codes relate to new practices, new activities, interactions, changes in behavior, and attractiveness. The initial codes ranged from corporations' motives, program characteristics, startup expertise, knowledge to new business outcomes. We re-read and re-coded the data several times according to our evolving understanding of the data (Denzin \& Lincoln, 20 I I). As a final step, we labeled the first-order codes, and the data were fully re-coded three times, resulting in 67 codes. Examples of the first codes we used include 'attractiveness of talented people', 'development of new commercial leads', and 'understanding market trends'. The second phase of coding (Strauss \& Corbin, 1998) was essential to identify the relationships between these first-order codes and to place them in higher order themes. As with earlier stages, this was an iterative process that was conducted until all the data were accounted for. Overall, this process resulted in a more coherent theoretical framework through the identification of seven second-order themes. Examples of second-order themes include 'image and brand equity' and 'organizational practices and learning'. The second-order analysis was followed by a third phase, which led to the identification of four aggregate dimensions (Gioia et al., 2013). These dimensions represent key resources. A synthetized version of the analysis is presented in Figure I, linking the representative data associated with the first-order, second-order, and aggregate dimensions.

\section{From data structure to a dynamic model}

While our data structure highlights the emergent overarching theoretical dimensions, it does not explain the inter-relationships between these dimensions. Using our detailed data analysis, we organized the various concepts, themes, and dimensions into a model that represents the relationships between the variables (Figure 2). In a sense, the connecting arrows turn the otherwise static 'boxes' into a dynamic representation. As Gioia et al. (20।3, p. 22) indicate, "it is the arrows that set everything in motion'. In Figure 2, we summarize the fundamental dynamics at play for corporations in corporate acceleration programs and the way they allow corporations to obtain strategic resources.

\section{Findings}

We present the results of this study in accordance with the interaction dynamics of the strategic resources found in our dynamic model (Figure 2). In our presentation of the findings, 1st Order concepts

- Innovations held by startups (patents, copyright, new technologies)

- Sensing new opportunities

- Understanding market trends

- Scanning their external environments to spot new or untapped technologies, unexploited market needs and changes in customer preferences

- Learning about new technologies

- Appropriating new production \& design processes

- Attractiveness for talented people
- Attractiveness for different profiles

- Development of new commercial leads

- Improving internal and external image

- Improving brand equity

- Having a showroom for entrepreneurial innovation

- Having a cool place/site
- Co-experimentation of new prototypes

- Co-development of MVPs for quick testing

- Best management practices and management style

- Transforming their business models according to environmental changes (Integration/adaptation capability) 2nd Order themes

Innovation technologies
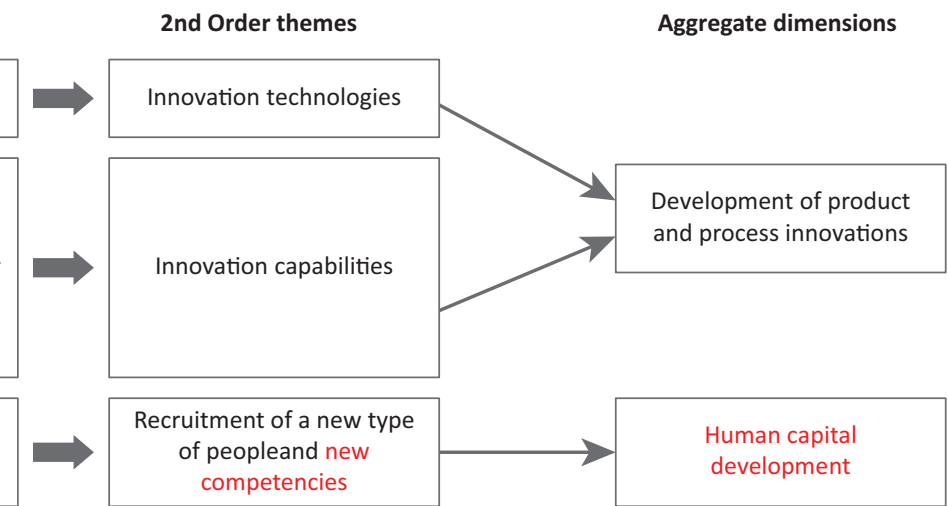

Recruitment of a new type of peopleand new competencies

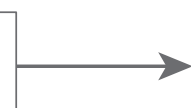

Human capital development

Aggregate dimensions

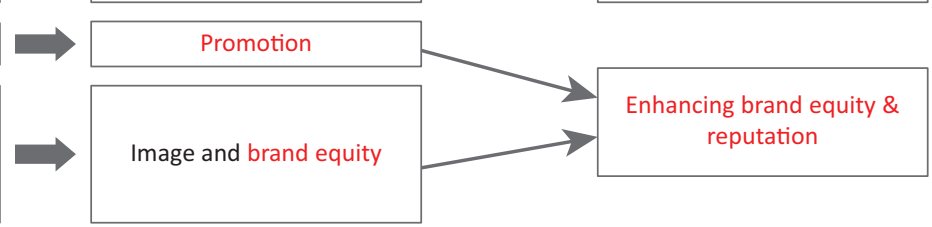

Figure I. Data structure

Note: In red, concepts that appeared to be new to the corporate accelerator literature. 


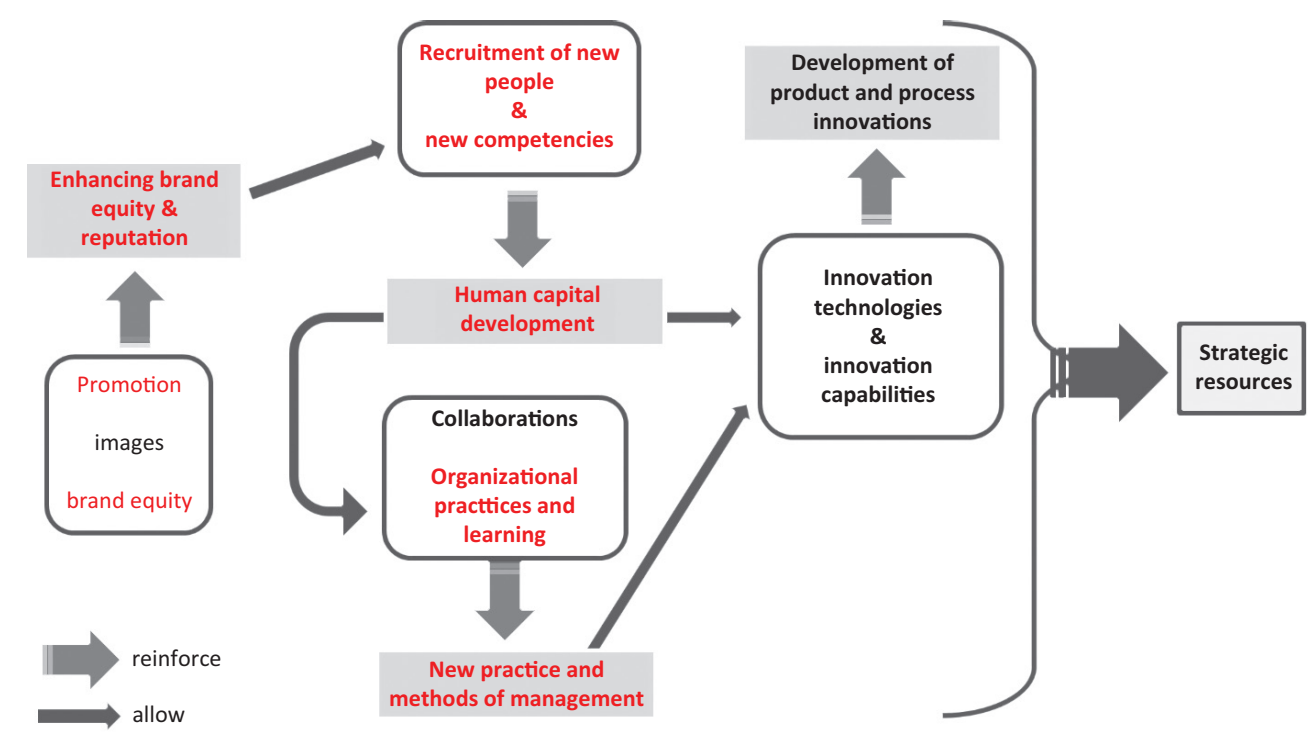

Figure 2. The various dynamics at play for corporations during corporate acceleration

Note: In red, concepts that appeared as new with respect to the corporate accelerator literature.

we coordinated and incorporated three data displays. Figure I shows the gradual data structure, Figure 2 shows the emergent model and Table 3 shows the additional supporting data, allowing the reader to discern and 'triangulate' the evidence from our findings. The following section is set out as follows: first, we discuss the resources that enhance brand equity and reputation, and help to attract new talented people. We continue with the resources that inform the emergence of new management methods. We end by showing how these dimensions interact and lead to two forms of innovation: those related to the product and those related to the process.

\section{The corporate accelerator as a source of brand equity and enhanced reputation}

The analysis of our data shows the different steps adopted to acquire and use the different resources. These steps, as explained below, allow corporations to move from consolidation of an external image to the final objective of innovation. The first step involves gaining visibility by improving their brand equity and reputation. We find that corporate accelerators are viewed by the market as a positive sign of openness and modernity, enhancing the way customers and key stakeholders see the corporations involved ( $\mathrm{P} / \mathrm{Cl} ; \mathrm{P} / \mathrm{C} 2)$. This is deemed to be especially relevant in sectors, such as banking (BNP) and telecommunications (Orange), as both have an old-fashioned and traditionalist image in the eyes of their customers and employees.

This branding and reputation provide the corporate accelerator and, in turn its corporation, with the opportunity to 'promote themselves' as they become attractive and visible to startups (IBE/CI; IBE/C2). One of the examples of this is BNP bank's WAI accelerator that gained a reputation for the solid help it gave to startups and is now at full capacity with waiting lists of new startups that want to join it. Capgemini has seen the same result, as the legitimate evidence of positive outcomes has led to a natural flow of startups reaching out to it.

As for Reputation, while this is an intangible resource, the corporate accelerators acknowledge that reputational gains are, in fact, the easiest element to measure, helping them to justify their existence with regards to the corporation. This is because the accelerators are frequently talked about in the press, giving the entity free publicity whose value can be quantified in monetary terms (IBE/CAI; IBE/CA2). For Le Village by $\mathrm{CA}$, for instance, its value is equivalent to a communications campaign worth I million euros a year. A final aspect that adds to gains in reputation and image is the short acceleration time frame (3-6 months), which means that there is a permanent turnover of startups, thereby increasing the chances of reaching a wider audience and with, afterwards, an effect on the new commercial opportunities created (P/CAI).

\section{The corporate accelerator as a source of human capital development that leads to new management methods}

The brand equity and reputational gains produced by the accelerator boost the corporation's ability to attract, recruit, and access 'new people and new competencies' (RNP\&C/RI; 
Table 3. Data-supporting interpretations (sample of verbatims)

Enhancing brand equity and reputation - Promotion (P)

Representative $\quad$ P/CAI ${ }^{4}$ : 'WAl describes itself as a business accelerator; the important thing is to do business and to find customers'. (WAI)

quotations from corporate accelerators (CAs)

'We have the possibility to develop networking opportunities internationally'. (WAI)

'A startup can access all the services from the rest of the villages in other parts of France. The links between villages create business opportunities'. (Le Village by CA)

'Startups have an advantage when they start to collaborate with La Poste and test its marketing to search for new customers'. (Start'inPost)

'The aim is to develop commercial partnerships between the different product lines of Orange (or its partners like La Poste) and the startups'. (Orange Fab)

Representative quotations from startups (S)

'The accelerator looks for customers with very concrete problems. The accelerator is business oriented'. (Energic/WAI)

'The idea was to target numerous clients from the bank with product offers and to develop advice from researchers and experts in the field'. (PhD Talents / WAl)

'We look for opportunities to work with Orange Fab clients from abroad (we've been introduced to leads in Korea and Japan via Orange Fab)'. (Global Exam / Orange Fab)

'We're accelerated in two different business accelerators because we find that each of them gives us opportunities to meet potential customers'. (FanVoice / Le Village by CA)

'Creation of a commercial partnership: purchase of terminals and commercial operations'. (Peeksprint / Start'inPost)

Representative quotations from corporations (C)

$\mathbf{P} / \mathbf{C I}$ : 'Our accelerator is a channel to help startups come to us'. (Capgemini)

P/C2: 'When we first opened, we had to wait for startups to talk about us so that others would come, and now we have a waiting list of those who want to join thanks to a "word-of-mouth" effect'. (BNP)

'I'm part of a new type of ambassador trained to sell products specifically aimed at startups'. (BNP)

Enhancing brand equity and reputation - Image and brand equity (IBE)

Representative

IBE/CAI: 'To develop our reputation, we've sponsored articles on FrenchWeb where we asked business leaders to talk about quotations from CAs

Start'inPost. We also partner several events: Web2Day, the Blend Web Mix in Lyon, the Salon des Entrepreneurs and Futur en Seine in Paris'. (Start'inPost)

IBE/CA2: 'We organize lots of seminars for larger groups, sometimes including startup showrooms'. (Le Village by CA)

'The group La Poste works on creating a physical space for innovation that could also become an incubator or a place to host startups'. (Start'inPost)

'One of the impacts is the improvement of our image (media impact and the budget is estimated at a value of I M $€$ /year)'. (Le Village by $(A)$

Representative quotations from startups (S)

'One of the secondary benefits is getting media attention based around the startup'. (Neuroprofiler / Orange Fab)

'The use of the accelerator as a showroom and fablab allows us to develop an MVP and increases its visibility with CG customers'. (XXII / Capgemini)

'We found it difficult to reach the end customers, but it was easier with the Capgemini brand as you can find them very easily (Schneider, General Chief of the Armies, Arkea, etc.)'. (Copsonic / Capgemini)

'The outcome is very positive in terms of visibility, with a great backup name and a great reputation'. (XXII / Capgemini)

Representative quotations from corporations (C)

'I know we were able to improve the government's image'. (Public Sector)

IBE/CI: 'We have the opportunity to invite our clients to breakfast-type events where we showcase startups and new technologies'. (BNP)

IBE/C2: 'Of course, this helps us to improve our image'. (Orange)

'We have some big events targeting journalists and media to showcase innovation'. (Orange)

Elements of transition towards recruitment of new people and competences (RNP\&C)

Remarks that shed light $\mathbf{R N P} \& \mathbf{C} / \mathbf{R} \mathbf{I}$ : 'The idea is to show that BNP Paribas can be an important player in innovation, especially when it comes to the on the dynamics between the elements (cf. the arrows in fig. 2) (R) image new graduates have of us'. (WAI)

'Thanks to word-of-mouth on BetaGouv, we have a huge number of public employees that want to come to us to pitch their solutions. People that would have never had an opportunity to generate solutions to existing problems, problems we want to solve'. (BetaGouv)

RNP\&C/R2: 'I started interacting with BetaGouv because they launched a project in my region'. (Public Sector)

'I feel like I landed in my position by chance. I was originally recruited as an electronics engineer and then when the Village CA arrived, they asked me to work on innovation and to start doing intrapreneurial projects'. (CA) 
Table 3 (Continued). Data-supporting interpretations (sample of verbatims)

Human capital development - Recruitment of new people and competencies (RNP\&C)

Representative 'The idea is to show that BNP Paribas can be a major player in innovation, especially when it comes to the image new graduates quotations from CAs have of us'. (WAI)

'The accelerator could become a career accelerator'. (Betagouv)

'I think the accelerator attracts the "Cream of the crop" of the public administrator'. (Public Sector)

RNP\&C/CAI: 'The accelerator also helps us to recruit students (I 000 visited our website last year)'. (Capgemini)

'The real product is the creation of "makers" within the administration'. (Betagouv)

'The incubator must allow the intrapreneurs to find solutions to problems with a certain degree of autonomy'. (Betagouv)

Representative

quotations from

corporations (C)

'We have a pool of talent that we can call "geeks" that benefit from interactions with startups'. (Orange)

'Our consultants can spend up to 6 months working in a startup, which is a good way to retain talent'. (Capgemini)

RNP\&C/CI: 'The accelerator really attracts the best and most talented people in the public service'. (Government)

RNP\&C/C2: 'The accelerator gives us the chance to recruit, but also to keep our existing talent and to give them a new sense of purpose'. (Capgemini)

Elements of transition towards new management methods (NMM)

Remarks that shed light $\mathbf{N M M / R I}$ : 'I was very positively surprised to be able to experiment with all of this, with new solutions and working methods. It on the dynamics (cf. the boosted my willingness to do intrapreneurial projects'. (Public Sector)

arrows in Fig. 2) (R)

'Three years ago, I decided to work with the accelerator because I saw that it helped us to rejuvenate and break away from bureaucratic forms of public administration'. (Public Sector)

NMM/R2: 'We're aware that we need to learn how to speed up decision-making, how to be able to work more flexibly and how to question ourselves more'. (Capgemini)

New management methods and practices - Collaboration (Coll)

Representative Coll/CAI: 'A 5-month co-experimentation program for new products'. (WAI)

quotations from of CAs

'The aim of Start'inPost is to help the group launch new innovative services in order to foster partnerships between startups and companies within the group'. (Start'inPost)

'The reason for having the accelerator is to create relationships, speed up the startup's development process and help it to use the strengths of La Poste group'. (Start'inPost)

Coll/CA2: 'Orange Fab is the architect of the interaction between large groups and startups (getting a commercial partnership is the most difficult thing to achieve). We're a third party that must act as a headquarters for startups'. (Orange Fab)

'The idea is to come out with an MVP and to get into production at the level of startups (to do something testable very quickly)'. (Capgemini)

'The idea is to change the customers in their way of doing things with the partners (ideation process)'. (Capgemini)

Representative quotations from startups (S)

Representative quotations from corporations (C)
Coll/CA3: 'The accelerator could be considered as a platform for innovation between startups and corporations'. (WAI)

'The accelerator acts as a security, a sort of collateral that works with startups, contacts and companies and helps the entrepreneurs to follow the firms' rhythm. It's a liaison between both parties'. (Energic /WAl)

'After our incubation, we found the results positive, an approach that's very healthy in Start'inPost because we have access to financial resources and we work with one of the group's subsidiaries (20,000€) to develop a product'. (Visiperf / Start'inPost)

'The project was difficult because there were a number of changes in terms of people within the organization. We launched in a few weeks and found that our representatives at Orange Fab played a key role in catalyzing and opening doors for us'. (Global Exam / Orange Fab)

'XXII looked for an "integrator" provider for its development, seeking complementary competencies within the two institutions'. $(X X \| / C G)$

Coll/CI: 'One of our key targets is to train corporations and businesses on how to collaborate with startups'. (BNP)

Coll/C2: 'We have many examples of co-experimentation and collaboration, like Hello Charlie which was co-developed'. (CA) 'We listen to the feedback of business developers working in the field who let us know if the solutions proposed by startups are effective'. (La Poste)

'Without a doubt, the co-construction of new solutions is the most important attribute of an accelerator for us'. (Public Sector) 'Concretely we want to create a commercial accelerator that works efficiently in BtoB, and to do so we create moments of sharing and meet-ups between companies and startups'. (CA)

'We create moments of sharing and places where corporations and startups can meet'. (CA) 
Table 3 (Continued). Data-supporting interpretations (sample of verbatims)

New management methods and practices - Organizational practices and learning (OPL)

Representative 'The aim is to speed up Crédit Agricole's digital transformation and to accompany the new forms of business creation

quotations from CAs (startups)'. (Le Village by CA)

'Le Village works a lot with consulting firms and the startups help us to legitimize this role. It's a new leverage and development model for us; selling services to corporations'. (Le Village by CA)

'We have very lean management practices; every week, each startup (team) has a minute to talk about progress and issues. Everyone knows about everything and this leads to internal help and team handling of issues'. (Betagouv)

'The incubator is an autonomous area for public employees: we have to get our boss's agreement as every area is different and this creates some tension within the organization'. (Betagouv)

OPL/CAI: 'Working with startups helps us to save time, be more proactive and to think "outside the box"'. (Start'inPost)

OPL/CA2: 'The internal processes of a KA mean we have to spend time on the idea-to-project stages. A startup can do this in as little as six months, which allows us to test our ideas faster'. (Start'inPost)

OPL/CA3: 'We find we can test our own rules and governance to work differently with the startups'. (Orange Fab)

'Orange Fab will start working on the acceleration of other large groups (to build on solutions to develop the mindset needed to be able to work with startups)'. (Orange Fab)

Representative 'We're going through a pivotal period and we find the help we need to commercialize the product. Strategically, it's important to quotations from startups (S)

Representative quotations from be close to La Poste'. (Visiperf / Start'inPost)

corporations (C)

'We have kept the goal to have an intrapreneurial mindset, and more importantly, to share this goal with other people'. (Public Sector)

'I can tell you that our employees often meet up with Startups, to see how the ecosystem works, to meet the team'. (CA)

OPL/CI: 'The accelerator lets us acculturate our employees in innovation and digital transformation'. (CA)

'We have a startup working inside the walls of La Poste which makes it easier to pass on information'. (La Poste)

OPL/C2: 'Without a doubt this changes our organizational practices. Don't forget, we're collaborating with 900 startups at the moment'. (CA)

Elements of transition towards products and process innovations (I)

Remarks that shed light I/RI: 'Our local partners were a bit reluctant, but our users were very interested to see how these new operating methods on the dynamics (cf. the produced results'. (Public Service)

arrows in Fig. 2) (R) 'What businesses need to collaborate with startups is trust, and we give them this trust so that they can open up to the development of new solutions'. (WAI)

'I used to work as a business developer for La Poste and now I work in a startup accelerated by La Poste because I can relate to the challenges and I can now help to develop solutions'. (La Poste)

Development of products and process innovations - Innovation technologies (IT)

Representative quotations from CAs

Representative quotations from startups (S)

Representative quotations from corporations (C)
'We acquired the technology of one of our incubated startups; Julie, an Al activated assistant'. (Orange Fab)

'The incubator has a fablab. It's an amplified innovation logic. Our commercial representatives are trained to bring our clients to the accelerator'. (Capgemini)

IT/CA I: 'Le Village by CA gives firms insights in terms of new emerging trends and technologies, even beyond their own industries'. (Le Village by CA)

'This is a tripartite operation; the customer pays an MPV which is produced by a startup and then hosted within CG'. (Capgemini) 'Our startup, Api.gouv.fr, is a catalog of all the public APIs that facilitate requests for access to government information'. (API.gouv / BetaGouv)

'Each entity provides its own service; the startup sells licenses for its technology and CG offers this service to customers'. (Copsonic / Capgemini)

'Our vision is to work with the different business units at Orange. As of today, this means TOEIC training via the Orange box for customers and offering Orange employees a global exam'. (Global Exam / Orange Fab)

IT/CI: 'Without a doubt the accelerator's most important function is the co-construction of prototypes'. (Public Sector)

'I consider startups as business partners. They help me offer my customers innovation and services'. (Capgemini)

IT/C2: 'In the past 6 months we have conducted 38 co-experimentation programs with companies'. (BNP)

'Innovation, co-development, new technologies, access to market trends, this is what we're looking for'. (Orange)

IT/C3: 'Thanks to the startups, we can offer our customers solutions and innovation without having to do it ourselves'. (Capgemini) 
Table 3 (Continued). Data-supporting interpretations (sample of verbatims)

Development of products and process innovations - Innovation capabilities (ICs)

Representative

quotations from CAs
'It allows us, on the one hand, to do a market search for startups that can be interesting for La Poste group and, on the other, to identify new trends and alert the group's innovation services so we can decide whether to pursue projects or not'. (Start'inPost)

ICICAI: 'The idea is to work on Open Innovation inside the village and to look for inspiration from other sectors'. (Le Village by CA)

IC/CA2: 'The idea of the incubator is to change the practices and uses that can lead to different forms of innovation'. (Betagouv)

'There's a determination to support the new activities in La Poste (eco-mobility, energy transition, sustainability, new services for individuals, connected objects, etc.)'. (Start'inPost)

'The lab is a digital transformation service available to CG customers'. (Capgemini)

Representative quotations from startups (S)

Representative quotations from corporations (C)
IC/SI: 'We collaborate with a team from La Poste that develops a new service. The idea is to use us to transform La Poste via the new services'. (Peeksprint / Start'inPost)

'The idea was to target numerous clients from the bank with product offers and to develop recommendations from researchers and experts in the field'. (PhD Talents / WAl)

'This is a movement that allows us to renew way the administration works and to break down the hierarchies which can very quickly exhaust people who are conveyors or drivers of innovation'. (Public Sector)

IC/CI: 'We have set a number of new processes to identify startups, to incorporate them and to seek new technology'. (Orange)

IC/C2: 'We have put new processes in place; we have a team that does screening and when a solution is scanned, we recommend it globally and put a strategy in place to work alongside the startup and make a business plan to allow the solution to operate'. (Capgemini)

'Yes, startups help us to go faster and speed up the development of solutions for our customers'. (Capgemini)

WAI, We Are Innovation; BNP, Banque Nationale de Paris; RNP, Recruitement of New People.

RNP\&C/R2). Accelerator managers agree that opening an accelerator has an excellent impact on the customer and employee perceptions of the corporation, and also boost potential recruitment and attracts new talent due to the enhanced organizational dynamics they perceive (RNP\&C/ CAI). The two corporate accelerators from the banking industry in this study admitted that they were created to revamp the banks' image with individual and professional customers. Another reason for creating an accelerator is to revitalize the firm's image with young graduates, as in the case of Capgemini, which considers it vital for the highly competitive job market in France. Every year, this accelerator hosts over 1,000 students to identify and recruit high potential graduates. The diversity of profiles these new recruits offer also allows corporations to import new skills from these employees and different managerial attitudes (RNP\&C/ $\mathrm{Cl}$; RNP\&C/C2).

We found that some corporations (four out of six) benefit from new management practices arising from the recruitment of new people (NMM/RI and NMM/R2); however, not all of them consider it important or strategic to engage in learning new practices and management methods. Thus, we found that the two corporations that make no effort to incorporate the managerial practices of startups into their organization consider such practices to be out of step with the way the organization currently works. The other four corporations actively seek to learn and benefit from new organizational practices and use accelerators as a liaison between 'two worlds' resulting in changes to their work-related practices (OPL/CAI, OPL/CA2, and OPL/CA3). The head of the Start'inPost accelerator explained that 'working with startups allows us to gain time, to be more proactive and to think "outside the box"'. Another case is Orange Fab that manages the startups but can also create new ways of working inside the corporation. For instance, the Orange Fab team organizes separate debriefs between a business unit and a startup following a meeting to examine whether people have the same perception of the commercial opportunities. This has led to some specific practices being introduced to help the business team learn to work with the startups, resulting in new management routines and styles (OPL/CI and OPL/C2). The manager of the corporate accelerator hopes to offer this organizational function or competence to other large firms as, in the short term, Orange plans to operate acceleration programs for other large corporations.

Another key managerial method includes collaboration (Coll/CAI, Coll/CA2, Coll/CA3, Coll/Cl, and Coll/C2) where Capgemini, for instance, allows talented consultants to work inside a startup for up to 6 months. The learning of new management practices may also be customer oriented, as explained by the head of WAI, where taking advantage of the accelerator is 'a way to acculturate the customer teams to innovate'. 


\section{The corporate accelerator as a means to combine resources that lead to innovation}

With this dynamic in place, corporations seek to increase their product and process innovations (IT/CAI, IT/CI, IT/C2, and IT/ C3). The first and 'easy' way to do this is to acquire the innovation held by a startup. One of the examples includes the acquisition of Julie, an IA-based receptionist's name, developed by a startup and used at Le Village by CA.

The second way to increase such innovations involves co-experimentation programs between startups and customers. These programs provide accessible and valuable solutions to existing customers of the corporation. One of the examples is BNP's accelerator (WAI), which connected a large vacation resort with a startup specialized in phone booking analyses. In the case of BetaGouv, all startups are required to have an 'internal client' after 6 months, which will put the service solution created to use. Meanwhile, Orange Fab allows teams to test and evaluate the viability of new products and the possibility to cross-sell, and Start'inPost's startups are encouraged to address and determine new market opportunities and trends. A last example includes Capgemini that uses startups to enhance its customer offer and provide faster solutions to become an 'integrator of technological solutions' (Head of Capgemini accelerator).

The interaction between innovation opportunities and new processes leads to the emergence of Innovation capabilities. When it comes to innovation as a skill, some corporations have learnt from the dynamism of startups and act as innovative solution testers (IC/CAI and IC/CA2). At La Poste, new ideas can receive up to $20 \mathrm{~K} €$ in funding to collaboratively test new offers within a business unit. The aim is twofold: first, to create innovation in new fields where the corporation has few competencies and, second, to develop a field test approach in real-life environments.

Thanks to accelerators, corporations also create an innovation capability as their employees become capable of sensing new opportunities and scanning external environments to spot new or untapped technologies (I/RI). This means that explicit processes and criteria will be matched with the ability to identify the upcoming trends and technologies in a variety of businesses. Orange, for instance, insists on the need for its teams to regularly interact with startup founders to seek opportunities for developing joint offers for their customers (IC/SI, ICl $\mathrm{Cl}$, and IC/C2) using a startup's services or its technology either to improve the value of a bundle of services or to produce technological solutions. This is also the case at WAI or Le Village by CA, where teams from the corporation are encouraged to talk to their own customers in the private banking sector, for example, to find the best way to help them diversify their portfolio in view of the promises of emerging technologies.
Understanding market trends is at times followed by access to innovation technologies. This innovation comes first in the form of a product or service that requires corporations to use their accelerators as sources of new technologies (such as Big Data, Machine or Deep Learning, Block Chain, new applications for IA, connected objects, energy efficiency sources, and disruptive business models). Another example includes Start'inPost that identifies new services for individual customers in the silver economy sector at La Poste or connected objects to compensate for the decline in revenue from its traditional core business (postal deliveries). A last example is BNP in the financial sector, which has created 'WAI Connect' in some smaller towns, a program that provides specific resources designed to connect firms and startups in different places and specific sectors (predictive data mining, data security, green energy, etc.), thus helping them to do business together. The idea is to build a regional network between startups and B2B bank customers.

\section{Discussion: The corporate accelerator: a new source of strategic resources for corporations}

The study findings reveal, first, that startups operate within what is, in fact, a strategic factor market, and that corporations must set up a dynamic process to access it. We then explain how corporate accelerators act as a 'mode of access' or 'entry point' for the resources held by startups to become accessible to corporations. Following this, we show how this dynamic process provides corporations with a new set of valuable resources that are introduced by startups and then further developed by the corporations that continue to work with them.

\section{The startup market within the corporate accelerator as a strategic factor market}

Our fresh understanding of the inherent characteristics of the market in which startups deliver resources led us to define them as a new form of strategic factor market (Barney, 1986). Such SFMs provide uncertain information regarding the advantages that the resources can offer a firm, market failures that allow firms to acquire resources at low cost, and a chance to lower the risks accruing to the acquisition of such resources (Barney, 1986; Leiblein et al., 2017). Within the scope of our study, positioning the startup environment as a new strategic factor market gives us an opportunity to explore how these resources are accessed, with a focus on the specific case of corporate accelerators.

The advantage of developing a corporate accelerator is explained by several factors. First, businesses are able to reduce the transaction costs and risks associated with the uncertainty 
as to whether the resources will produce value. In line with Foss (20ll), we suggest that corporate accelerators allow firms to 'evaluate' and 'test' the potential value that these resources may create. This means that firms can consider their corporate accelerator as an investment strategy, providing the firm an 'informational advantage' (Makadok \& Barney, 200I), improving the ability of managers to better evaluate the 'valuation of the resource', and providing an additional obstacle to prevent competitors from acquiring the resource (Foss, 20 I I).

A second factor includes the need for corporations to give enough time for their startups to examine the viability of their product or service and their business model. In this sense, as the startup is neither acquired nor absorbed, the acceleration process can be seen as a type of 'leasing' (Mehran et al., 1999). Being the leaser, the accelerator acts as an intermediary that can decide on the interest of renewing (or not) a contract or partnership with the startup. Talking about a 'lease' arrangement enables us to position the startup within an SFM, where resources are not acquired but rather are 'rented', 'tested', or 'absorbed' for a fixed period, during which the corporation retains the possibility to interact and generate new business opportunities through this partnership.

A third factor regarding the benefit of having a corporate accelerator is that it reduces the huge gaps and differences in the modes of operation and agility of startups compared with corporations (Moschner et al., 2019). Viewed from a collaborative perspective, getting a startup to join a corporation's operations is liable to generate huge cultural differences, impose a new operational strategy on the startup (due to the liability of size), and lower the chances of efficient transmission of resources (lborra \& Dolz, 2007).

A final aspect to consider is that corporate accelerators enable corporations to switch from a traditional type of interaction, which consists of simply acquiring a startup or its innovation (Kohler, 20 16; Richter et al., 2018; Shankar \& Shepherd, $2019)$ to finding new ways to collaborate in the development of new products or services, and potentially being inspired to improve their management methods and even implement managerial innovations.

\section{What are 'startup-held' resources and how are they acquired within the corporate accelerator setup?}

While our proposal to treat the startup environment as a strategic factor market is original, many previous studies have explored the role of corporate accelerators in providing corporations with valuable resources (Kohler, 2016; Richter et al., 2018; Shankar \& Shepherd, 2019). Contributing to this literature, the study findings help us to understand that the corporate accelerator itself is an enabler in the creation of valuable resources and capabilities (other than those introduced by the startup), and that the development of such resources follows a certain dynamic that leads to the emergence of new products, services, or processes for the corporations involved.

We show that a larger number of valuable resources than those previously acknowledged can be found in SFMs where startups operate, and are also generated as corporations access these markets. The corporate accelerator's power lies in granting access to an ecosystem, working as a startup sourcing mechanism, fostering the development of capabilities, generating the new processes needed to operate with them and creating new value-oriented activities or products. This is in line with Pauwels et al. (2016) who suggested that the 'ecosystem builder' is a type of accelerator typically set up by corporations that wish to develop an ecosystem of customers and stakeholders based on their issues.

Interestingly, the innovation access mechanism requires a number of stages, which, to our knowledge, has not previously been discussed in the literature. First, the accelerator must gain visibility to enhance the corporation's brand equity and reputation. In this respect, the corporate accelerator provides an effective means to revamp a corporate identity as it lends the corporation's positioning to younger, more vibrant firms. These new images and visibility have a knock-on effect as the corporation becomes more attractive, enabling it to attract new recruits and thus develop its human capital, followed by new management methods and practices. Finally, startups collaborate (with each other and corporation employees) and generate new products and services, which results in the development of product and process innovations, as well as a renewed capacity for innovation within the corporation. We present the three main stages below.

The first stage is when the corporate accelerator, by facilitating the emergence of new spaces that foster exchanges and creating a showroom to share the firm's entrepreneurial activities, generates an improved internal and external image among stakeholders (Richter et al., 20 I 8). This progressively leads to a measurable financial impact in terms of brand equity. The new identity and branding provided by the accelerator act as a way to conquer younger generations, thus creating a more contemporary image that facilitates the recruitment of experts or young graduates. As Kohler (20 I 6, p. 35 I) argued, 'tapping into the pool of entrepreneurial talent can help not only to attract new people, but also to retain existing talent'. Furthering this view, we found that the people involved in the accelerator's activities are also more diverse in nature as the corporate accelerator privileges competencies over position and, apart from innovation or product development roles, gives people the chance to use their time to produce or co-produce new commercial leads.

The second stage is when the collaboration and diversification of the activities undertaken by startups lead to the adoption of new management practices that facilitate the integration 
of new human capital (mostly knowledge) through a fresh set of managerial practices. A research study on startup management has shown that many of these ventures have management practices that can be extremely interesting for firms to learn (Kohler, 2016). The lean startup concept, for instance, has the potential to induce management practices that can ultimately lead to innovation, adaptability, and growth (Ries, 201 I). Through the intermediation of accelerators, firms can have teams of employees who test some of these management and work practices while, at the same time, learning about new concepts, tools and operations.

The third stage is that of interaction. Co-production is a key discovery, as, in addition to what has been said about open innovation and collaboration (Kohler, 2016; Richter et al., 20 I8), we find that corporate accelerators incite startups not only to resell existing products or to make them available to their staff but also to jointly generate new commercial solutions, prototypes, and proof of concepts for internal and external clients. This renewed ability to co-develop solutions not only nurtures the innovation capacity of corporations but also has a circular effect on the ability of employees, customers, and suppliers to collaborate. Collaboration also helps to promote new service offers that are either proposed by the startups or are already available in the firm's product portfolio. An additional finding is the usefulness of corporate accelerators acting as intermediaries that provide the startup's commercial and intermediation activities with otherwise non-existing interactions.

In the long run, the formalization of an innovation strategy through the creation of the accelerator, which leads to innovation strategy branding and enhanced awareness among stakeholders, also fosters the development of human capital (skills that lead to sources of knowledge) and the introduction of new management practices, thereby boosting the development of innovation and innovation-oriented processes (Fréchet \& Goy, 2017; Kohler, 2016; Shankar \& Shepherd, $2019)$. Innovation as an outcome of corporate accelerators resonates with the existing literature (Kupp et al., 2017; Shankar \& Shepherd, 2019), which clearly states that businesses may either use the accelerator to access new innovation (resources) or to learn how to innovate (capabilities) by interacting with startups (Weiblen \& Chesbrough, 20I5). We add to this observation by showing the importance of the resources supplied by startups as a way of providing not only an appropriate input for a stream of valuable innovativeness to develop but also an appropriate managerial, human, and strategic fit with the firm.

Innovation within corporate accelerators serves both an internal and an external purpose. Internally, the corporate accelerator aims to develop innovation competencies and/or product or service innovation for the corporation by selecting startups that have an interesting product, service, or technology, which matches its primary business and can help it to be more innovative (internal purpose). The external purpose includes selecting startups with an interesting product or technology that can match the needs of the firm's customers, thus helping it to be more innovative.

Finally, we acknowledge that corporations may have different primary goals when creating a corporate accelerator (Prexl et al., 2019) but that thanks to the acceleration dynamic, all of them are likely to gain access to strategic resources or skills, such as organizational practices and learning. We also acknowledge that the dynamic and the relevance given to each stage might be different: while some accelerators may emphasize internal branding (BetaGouv), others will adopt a wider stakeholder perspective (Le Village by CA). Furthermore, this research study indicates that in the specific case of acquiring new management skills, some corporations may feel that their size and business dynamic form limitations to the acquisition of such resources and make a strategic choice not to integrate them.

This diversity of actions and processes is very important as it validates the notion of startups as SFM where corporate accelerators can identify strategic resources that are different for all firms, which will also have different processes for appropriating them. While some corporations want to create independent and agile spaces for innovative operations (e.g., Orange Fab and WAl), others want to avoid impacting the dynamics and value of the resources through a structure that can help leverage their capacity to host multiple intakes of newcomers (e.g., Betagouv and Capgemini). Meanwhile, other firms seek to use accelerators as a way of accessing other sectors outside their primary activity sector (e.g., Start'inPost) or simply to make the accelerator itself a business unit with an independent economic model (e.g., Le Village by CA).

\section{Conclusion}

Our research study set out to explore a novel perspective of the resources that firms may access by hosting startups in corporate accelerators. We outline the mechanisms by which resources are either used, integrated, or acquired by corporations. Adopting a conceptual framework anchored in the RBV and the SFM perspective, this article marks a decisive step forward by showing how the world of startups can be viewed as a new type of SFM from which corporations can draw strategically relevant resources. We provide some clear contributions to the literature in both areas. First, we contribute to the literature on SFMs by integrating the world of startups as a new sphere in the search for and acquisition of resources with the potential to become a source of competitive advantage. We believe that this new way of understanding these resources can help advance the debate on the role and efficiency of corporate accelerators. Second, this study contributes to the RBV research stream by demonstrating its potential dynamism. 
We show the extent, value, and capacity that corporations have in acquiring resources other than those brought in by startups. To remain consistent with the RBV, the definition of 'strategic resources' that we retain encompasses all dynamic, knowledge-/process-based aspects of resources (Foss, 20 I I) owned or controlled by a firm to sustain its competitive advantage over time (Barney, 1991). Therefore, while the strategic resources discussed in the first stages are mainly individual or organizational, we are fully aware that they can also be dynamic. However, this study shows that dynamic capabilities are especially present in the last stages. Reconfiguring capabilities is central to renewing or transforming the organizational resources and capabilities already present in a corporation.

Our study findings have several important managerial implications. Generally speaking, we view the need for accelerators as a way to drive innovation and foster the acquisition of valuable resources. More specifically, we provide evidence of the characteristics of these strategically relevant resources, as well as the appropriation mechanisms involved. In addition, we extend the often-limited vision many managers have of accelerators as simply a source of technological innovation that can only be acquired through participation in equity.

Corporate accelerators act as bridges to facilitate communication, interaction, and connections between the startup operations and the corporation. They can also inspire a firm's employees to develop more innovation themselves in an intrapreneurship kind of way. Finally, we provide some key insights into the strategic positioning of the corporate accelerator and the different value propositions that can be created, given the choice of services provided and the strategic view of the accelerator as an independent component, able to incorporate valuable, yet mostly intangible and hard-to-measure strategic resources. We also observed that these valuable resources are limited by the size of the startup, which means that their industrialization is dependent on the ability of the corporation to incorporate them into their regular operations.

In conclusion, we acknowledge the limitations of our multiple case review, given the inductive nature of our approach. First, reproducing the study in another geographical context could be instructive as all of our corporate accelerator cases are based in France and, more specifically, in Paris. It would be interesting to test our findings in similar areas in other countries. As spatial context may have a significant impact on entrepreneurial and innovation ecosystems, further research studies are needed to 'explore the possibility of transferring the theory beyond the context in which it was inductively discovered' (Shankar \& Shepherd, 2019, p. 17). Second, this study pertains to a specific point in time. It would, therefore, be interesting to conduct a longitudinal follow-up of the impact of corporate accelerators on the strategic positioning of some of the corporations identify whether the corporate accelerator serves as a major transformation tool for an organization over time. The limitations of this study provide an invitation to develop further understanding of the startup world as a strategic factor market in order to continue exploring the types of resources that such startups can provide, to gain new insights into the ways in which these resources can be better exploited (and measured), and to identify the additional characteristics that define the way corporate accelerators function and are managed as intermediaries providing access to such strategic resources.

\section{References}

Barney, J. B. (1986). Strategic factor markets: Expectations, luck, and business strategy. Management Science, 32(10), |23|-124|. doi: 10.1287| mnsc.32.10.1231

Barney,J. B. (|99|). Firm resources and sustained competitive advantage. Journal of Management, I (1), 99-120. doi: I 0.1 I 77/0 I 4920639101700 I08

Barney, J. B. (200I). Resource-based theories of competitive advantage: A ten-year retrospective on the resource-based view. Journal of Management, 27(6), 643-650. doi: I0.1 I 77/0 I 4920630 I 02700602

Barney, J. B. \& Arikan, A. M. (200I). The resource-based view: Origins and implications. In M. A. Hitt, R. E. Freeman \& J. S. Harrison (Eds.), The Blackwell handbook of strategic management (pp. 124-188). Blackwell Publishers Ltd.

Becker, B. \& Gassmann, O. (2006). Corporate incubators: Industrial R\&D and what universities can learn from them. The Journal of Technology Transfer, 3 I (4), 469-483. doi: I0. I007/s I 096 I-006-0008-6

Cohen, D. \& Crabtree, B. (2006). Qualitative research guidelines project. Retrieved from http://www.qualres.org/index.html

Cohen, S. \& Hochberg, Y. (20|4). Accelerating startups: The seed accelerator phenomenon. Retrieved from https://papers.ssrn.com/sol3/papers. cfm?abstract_id $=2418000$

Denzin, N. K. \& Lincoln, Y. S. (20I I). The SAGE handbook of qualitative research. Sage.

Eisenhardt, K. M. (1989). Building theories from case study research. Academy of Management Review, 14(4), 532-550. doi: 10.5465/ amr.2008.27745499

Foss, N. J. (201 I). Invited editorial: Why micro-foundations for resourcebased theory are needed and what they may look like. Journal of Management, 37(5), I4 I3-| 428. doi: I0. I |77/0 | 492063 I 03902 I8

Fréchet, M. \& Goy, H. (2017). Does strategy formalization foster innovation? Evidence from a French sample of small to medium-sized enterprises.M@n@gement, 20(3), 266-286. doi: 10.37725/mgmt.v23i3.534 I

Gioia, D. A., Corley, K. G. \& Hamilton, A.L. (20 I3). Seeking qualitative rigor in inductive research notes on the Gioia methodology. Organizational Research Methods, I 6 (I), I5-3 I. doi: I 0.1 I 77/ I 094428 I I 2452 I 5 |

Glaser, B. \& Strauss, C. (1967). The discovery of grounded theory. Aldine Publishing Company.

Grant, R. M. (|99|). The resource-based theory of competitive advantage: Implications for strategy formulation. California Management Review, 33(3), | |4- |35. doi: |0.2307/4 | | 666664

Gust, M. (2016). Global accelerator report 20 16. Retrieved from http://gust. com/accelerator_reports/20 I 6/global/

Gutmann, T. (2019). Harmonizing corporate venturing modes: An integrative review and research agenda. Management Review Quarterly, 69(2), |2|-157. doi: | 0. | 007/s | | 30 |-0| 8-0 |48-4

Hausberg, J. P. \& Korreck, S. (2020). Business incubators and accelerators: A co-citation analysis-based, systematic literature review. The Journal of Technology Transfer, 45(I), I 5 I-176. doi: I0. I 007/s I 096 I-0 I 8-965 I-y 
Iborra, M. \& Dolz, C. (2007). El papel del conflicto en la exploración y explotación de conocimiento en las adquisiciones. M@n@gement, IO( I), I-2 I. doi: I0.37725/mgmt.v23i3.5352

Kanbach, D. K. \& Stubner, S. (2016). Corporate accelerators as a recent form of startup engagement:The what, the why, and the how. Journal of Applied Business Research, 32(6), I76I. doi: 10.19030/jabr.v32i6.9822

Kohler,T. (20|6). Corporate accelerators: Building bridges between corporations and startups. Business Horizons, 59(3), 347-357. doi: 10.10 16/j. bushor.2016.01.008

Kupp, M., Marval, M. \& Borchers, P. (2017). Corporate accelerators: Fostering innovation while bringing together startups and large firms. Journal of Business Strategy, 28(6), 47-53. doi: I0. I I08/JBS-12-20 I6-0। 45

Leiblein, M. J., Chen, J. S. \& Posen, H. E. (2017). Resource allocation in strategic factor markets: A realistic real options approach to generating competitive advantage. Journal of Management, 43(8), 2588-2608. doi: | 0.1 | 77/0|49206316683778

Lippman, S. A. \& Rumelt, R. P. (1982). Uncertain imitability: An analysis of interfirm differences in efficiency under competition. The Bell Journal of Economics, / 3(2), 4 I8-438. https://doi.org// 0.2307/3003464

Mahmoud-Jouini, S. B., Duvert C. \& Esquirol M. (2018). Key factors in building a corporate accelerator capability: Developing an effective corporate accelerator requires close attention to the relationships between startups and the sponsoring company. Research Technology Management, 6/ (4), 26-34. doi: 10.1080/08956308.2018.147/274

Makadok, R. \& Barney, J. B. (200I). Strategic factor market intelligence: An application of information economics to strategy formulation and competitor intelligence. Management Science, 47(|2), |58|-1732. doi: I0.1287/mnsc.47.12.1621.10245

Mehran, H., Taggart, R. A. \& Yermack, D. ( 1999). CEO ownership, leasing, and debt financing. Financial Management, 28(2), 5-14. https://doi. org/|0.2307/366619|
Moschner, S. L., Fink, A. A., Kurpjuweit, S., Wagner, S. M. et al. (2019). Toward a better understanding of corporate accelerator models. Business Horizons, 62(5), 637-647. doi: 10.1016/j.bushor.2019.05.006

Pauwels, C., Clarysse, B., Wright, M. \& Van Hove, J. (20 I 6). Understanding a new generation incubation model: The accelerator. Technovation, 50, 13-24. doi: 10.1016/j.technovation.2015.09.003

Peteraf, M. A. (1993). The cornerstones of competitive advantage: A resource-based view. Strategic Management Journal, 14(3), I79-191. doi: 10. I002/smj.4250140303

Prexl, K. M., Hubert, M., Beck, S., Heiden, C. et al. (2019). Identifying and analysing the drivers of heterogeneity among ecosystem builder accelerators. R\&D Management, 49(4), 624-638. https://doi.org/ I 0. I I I I/radm. 12352

Richter, N., Jackson, P. \& Schildhauer,T. (2018). Radical innovation using corporate accelerators: A program approach. In N. Richter, P. Jackson \& T. Schildauer (Eds.), Entrepreneurial innovation and leadership (pp. 99-108). Palgrave Pivot.

Ries, E. (20I I). The lean startup: How today's entrepreneurs use continuous innovation to create radically successful businesses. Crown Books.

Serrano, C. J. \& Ziedonis, R. (2019). How redeployable are patent assets? Evidence from failed startups. Academy of Management Proceedings, I, |563|-|5635. doi: 10.5465/AMBPP.2019.260

Shankar, R. K. \& Shepherd, D. A. (2019). Accelerating strategic fit or venture emergence: Different paths adopted by corporate accelerators. Journal of Business Venturing, 34(5), 105886. doi: 10.1016/j.jbusvent. 2018.06 .004

Strauss, A. \& Corbin, J. ( 1998). Basics of qualitative research techniques. Sage. Weiblen, T. \& Chesbrough, H.W. (20I5). Engaging with startups to enhance corporate innovation. California Management Review, 57(2), 66-90. doi: 10.1525/cmr.2015.57.2.66

Wernerfelt, B. (1984). A resource-based view of the firm. Strategic Management Journal, 5(2), |7| - |80. doi: 10. I002/smj.4250050207 